\title{
Skeletal age and explosive strength in young volleyball players
}

\section{Idade óssea e força explosiva de jovens praticantes de voleibol}

\author{
Petrus Gantois ${ }^{\top}$ \\ Vanessa C. M. Pinto \\ Kezianne R. de Castro \\ Paulo V. João ${ }^{3}$ \\ Paulo M. S. Dantas ${ }^{1}$ \\ Breno G. A. T. Cabral
}

\begin{abstract}
Identifying different anthropometric, physiological and motor aspects is essential to obtain success in sports practice. However, these components may be developed in same age subjects differently, in part due biological development. The aim of the study was compare and correlate the explosive strength to biological maturation by sex, obtained by estimation of skeletal age based on anthropometric variables. The sample consisted of 239 subjects of both sexes, aged 10 to 13 years. Maturation was assessed by skeletal age predictive equation and upper and lower limbs explosive strength using medicine ball throw test and vertical jump, respectively. Skeletal age was assessed by skeletal age using a predictive anthropometrical based equation. Upper and lower limbs explosive strength were evaluated by medicine ball throwing test and vertical jump test, respectively. Post hoc analysis showed delayed biological development subjects had worst medicine ball throwing test performance than accelerated boys $(\mathrm{p}=0.001 ; d=0.96)$ and girls $(\mathrm{p}<0.01 ; d=2.01)$; regarding to vertical jump test, worst performance was also detected to maturational delayed boys when compared to accelerated ones $(\mathrm{p}=0.24 ; d=1.1)$ and girls ( $\mathrm{p}=0.007 ; d=0.75)$. Regression analysis showed skeletal age explained variance of $36 \%$ and $19.2 \%$ for boys and $45.2 \%$ and $16.1 \%$ for girls upper and lower limbs explosive strength. Skeletal age is positively related to upper and lower limbs explosive strength and show higher performance for accelerated biological development young players when compared to delayed ones, independently from sex.
\end{abstract}

Key words: Athletes; Motor skills; Puberty; Youth.

Resumo - Para se alcançar o sucesso no esporte, a identificação de diferentes aspectos antropométricos, motores e fisiológicos são imprescindiveis. Porém, esses componentes podem se desenvolver diferentemente em individuos na mesma faixa etária, em parte pelo desenvolvimento biológico. $O$ objetivo do estudo foi comparar e relacionar a força explosiva com a maturação biológica de acordo com o sexo. A amostra foi composta por 239 sujeitos, com idades entre 10 a 13 anos. A idade óssea foi estimada por uma equação preditora baseada em variáveis antropométricas. $A$ força explosiva de membros superiores e inferiores foram avaliadas através do teste de arremesso de medicine ball e de salto vertical, respectivamente. A análise de post hoc mostrou que os sujeitos com desenvolvimento biológico atrasado obtiveram o pior desempenho no teste de arremesso de medicine ball quando comparados com o grupo acelerado dos meninos ( $p=0.001 ; d=0.96)$ e meninas ( $p<0.01 ; d=2.01)$; em relação ao teste de salto vertical, desempenho inferior também foi observado para o estágio atrasado quando comparado com o grupo acelerado dos meninos ( $p=0.24$; $d=1.1$ ) e meninas ( $p=0.007 ; d=0.75$ ). Análise de regressão demonstrou que $36 \%$ e 19,2\% da variância no desempenho da força explosiva de membros superiores e inferiores foi compartilhada pela idade óssea dos meninos, e 45,2\% e 16,1\%, respectivamente, nas meninas. Conclui-se que a força explosiva de membros superiores e inferiores se relaciona de forma positiva com a idade óssea, sendo o desempenho destes componentes superiores em jovens com desenvolvimento biológico acelerado, quando comparados com o desenvolvimento atrasado, independente do sexo.

Palavras-chave: Adolescentes; Atletas; Habilidades motoras; Puberdade
1 Federal University of Rio Grande do Norte. Postgraduate Program in Physical Education. Natal, RN. Brazil.

2 Federal University of Rio Grande do Norte. Research Group on Physical Activity and Health. Natal, RN. Brazil.

3 University of Tras-os-Montes and Alto Douro. Research Center of Sports Science, Health and Human Development. Vila Real, Portugal.

Received: 14 March 2017 Accepted: 08 May 2017 


\section{INTRODUCTION}

To achieve success in sports, the identification of different aspects such as anthropometric, motor and physiological are essential, making them the main parameters of selection and identification of young athletes ${ }^{1,2}$. In intermittent sports, such as volleyball, athletes perform short-term high intensity efforts, with emphasis on explosive movements such as jump, hitting and blocking, what emphasizes muscular explosive strength as an important athletic attribute. Corroborating with this idea, Sheppard et al. ${ }^{3}$ in a time motion study showed that players performed at least one jumping movement and frontcourt players performed four blocks jump and three spikes jump during a rally. Besides, functional capacities such as jump height and upper limbs explosive strength has been reported as good volleyball discriminant function predictor ${ }^{4}$.

Athletic readiness has been presented as a required condition to sports initiation ${ }^{5}$ due to searching for immediate results. Thus, based on talent selection and identification system, young athletes with higher explosive strength performance may have a better selection chance. However, results achieved on early initiation may not reflect on athlete's future success. Therefore, it is necessary to identify parameters beyond athletics readiness during young athlete's development. During adolescence, same age subjects may have body size and physical performance distinguished regarding in part due to their biological development rate ${ }^{6,7}$, which varies according to $\operatorname{sex}^{8,9}$. For decades, studies highlighted biological maturity impact on functional performance, especially regarding to strength tests ${ }^{10,11}$. This works have reported accelerated biological development influence on increased body growth, strength and power performance when compared to same chronological age less matured peers. Besides, performance differences associated to maturity may explain the high advanced maturity youth prevalence in selection process ${ }^{2}$. However, according to Malina et al. ${ }^{1}$ these differences tend to be reduced with age and eliminated, suggesting that maturation is an important tool to diagnose young people growth, development and physical potential. In this context, maturation appears as an important component to be identified in athlete's selection.

Sexual maturation, somatic maturation and skeletal age are commonly used evaluation methods for maturational identification. Skeletal age predicted by hand radiography is considered the most appropriate method to estimate biological maturation ${ }^{12}$. Even though it is referred as a gold standard to assess biological age, radiography practical application is very restricted, mainly because it demands high-cost equipment and specialized technicians for radiographs interpretation in addition, it increases subjects radiation exposure. Because of these limitations, our group recently developed a non-invasive, easily accessible and interpretive method based on a skeletal age predictor model using anthropometric variables ${ }^{13}$. Therefore, this method allows a greater practical applicability for coaches and technicians estimate the young athlete's biological development. 
Due to volleyball physical and functional demands, it is likely that biological maturity might play a significant role in youth players selection and performance. However, body size changes associated to accelerated maturation may impact on body displacement actions against gravity as in vertical jumps and throwing movements which characterizes explosive strength. Therefore, it is necessary to identify how much biological maturation combined to body size predicts upper and lower limb explosive strength performance, sports success essential components. This could minimize future selection and orientation errors in young athletes talent selection process. This study was conducted in order to compare boys and girls upper and lower limbs explosive strength performance in different maturational stages, as well as to verify the relation between biological maturation assessed by skeletal age and upper and lower limbs explosive strength, in conjunction to body size parameters. It is hypothesized that both male and female accelerated players in maturity will show higher explosive strength compared to same chronological age less matured peers, besides, a positive relation of the skeletal age with these attributes will be identified.

\section{METHODOLOGICAL PROCEDURES}

\section{Sample}

Subject sample consisted of 239 young volleyball players, both sexes, aged 10 to 13 years (12.03 \pm 1.44 years), participants of a volleyball sport's initiation project in Natal - RN, Brazil. Sample selection was intentional and non-probabilistic and adolescents practiced, three training sessions per week, during two hour. Inclusion criteria included subjects participation on the sport's initiation project, between 10 and 13 years old, practicing volleyball for six months or more. Those individuals who refused to participate of the suggested tests, those with health problems that could impair test performance, missing from the collections for two days, as well as those ones with an injury history in the last three months were excluded from the study. Study was approved by local institution Ethics and Research Committee of Health Sciences Center (CAEE: 1249937/2015), following guidelines for data collection in humans, according to resolution $\mathrm{n}^{\mathrm{o}}$ 466/12 of 12/12/2012 of National Health Council, as well as the ethical principles contained in Declaration of Helsinki.

\section{Study design}

Present study is cross-sectional and correlational designed. Initially, all data collection procedures were explained to project coordinators and participants, and then a consent form was issued for responsible signature, as well as term of assent for study volunteers. After signed documents returning, subjects were submitted to anthropometric evaluation during the first three days in order to estimate the biological development. Motor tests were then performed to identify upper and lower limb explosive strength, which also occurred over a period of three days. The data collection was done at project activities. 


\section{Anthropometric measurements}

Body mass and stature were assessed using an electronic scale (Filizola ${ }^{\circledR}$ 110, São Paulo, Brazil), with a capacity of $150 \mathrm{~kg}$, divisions of $1 / 10 \mathrm{~kg}$ and a precision of 100 grams and a stadiometer (Sanny ES2020 ${ }^{\circledR}$, São Bernardo do Campo, Brazil) with a $0.5 \mathrm{~cm}$ scale, respectively. Arm corrected perimeter and triceps skinfold, with Harpenden ${ }^{\circledR}$ adipometer (John Bull, London, England) with $0.2 \mathrm{~mm}$ precision and humerus and femur biepicondylar diameter, with a metallic caliper (Cescorf ${ }^{\circledR}$, Porto Alegre, Brazil). The reliability of the measurements was tested by technical error of measurement $(<5 \%)^{14}$ and by test-retest coefficient $(>0.98)$. All procedures were performed by a single evaluator and followed guidelines of the International Society for Advancement in Kinanthropometry (ISAK) ${ }^{15}$.

\section{Upper limbs explosive strength}

Upper limbs explosive strength was determined by medicine ball throwing test according to recommended standards proposed by Gaya and Silva ${ }^{16}$, reported as a high reliability level test to evaluate upper limbs explosive strength ${ }^{17}$. The subject's was instructed to sit with his back fully supported on a wall, keeping his legs together and his knees extended. The medicine ball ( $2 \mathrm{~kg}$ ) was held close to the chest region and was thrown at evaluator's signal as far as possible. The marked distance was considered from the zero (wall) to the first point of contact of the ball to the ground. For each test, the best performance between two pitches was considered. In case of trunk movement at throwing time, attempt was discarded and a new pitch was requested in order to avoid influences in upper limbs strength measurements. All participants were familiarized with the test.

\section{Lower limbs explosive strength}

The protocol used to identify lower limbs explosive strength was counter movement vertical jumping test, proposed by $\mathrm{Komi}^{18}$, reported as a high validity and reliability measure test to estimate lower limbs explosive strength $^{19}$. The instrument used was a contact platform connected to Jump Test Pro 2.10 software (Cefise ${ }^{\circledR}$, São Paulo, Brazil). To perform the test, the patient was standing hands on waist, performing eccentric and concentric phase of the movement quickly, flexing the hip, knee and ankle joints. The subjects were instructed to land at same point of takeoff, keeping their legs extended, in order to avoid knee flexion. To minimize differences in measurement, the hands were held on the hips throughout the test. Three jumps were performed in a one-minute interval, and the best performance was recorded, with jumping height used to analysis.

\section{Skeletal age and maturation}

Subjects biological development was assessed through a mathematical model used to estimate skeletal age. Equation was determined by anthropometric variables using a multiple regression model. Only anthropometric variables that showed a significant correlation with the skeletal age obtained 
by wrist radiography, considered as gold standard, were included in the model. Predictor model was validated by Cabral et al., ${ }^{13}$ for both sexes youth Brazilian population aged 8-14 years ( $\mathrm{r} 2$ adjusted $=0.741$; standard error =1.24), according to the equation: Skeletal Age $=-11.620+7.004($ height $)+$ 1.226.Dsex + 0,749(age) $-0.068(\mathrm{Tr})+0.214(A c p)-0.588(H d)+0.388(F d)$.

Note: $\mathrm{Tr}=$ tricipital skinfold, $\mathrm{Acb}=$ arm contracted perimeter $\mathrm{Hd}=$ humeral bone diameter, $\mathrm{Fd}=$ femoral bone diameter and $\mathrm{Dsex}=0$ for males and Dsex $=1$ for females.

To determine maturation, skeletal age subtraction was used by chronological age in years (sum of months of life divided by 12). The maturation was stratified according to the following cutoff points for the study: delayed (result over 12 months negative for chronological age), normal (up to 12 months positive or negative for chronological age), or accelerated (Above 12 months positive in relation to chronological age $)^{9}$.

\section{Statistical analysis}

Normal distribution of data was verified by Kolmogorov-smirnov test. Data were reported on mean and standard deviation, and maturational stages on relative and absolute frequency. A univariate ANOVA was used to compare the dependent variables among the maturation levels. Eta squared partial (partial $\eta 2$ ) was used to determine the effect size of the variance. When necessary, Bonferroni's post hoc test was used to find the significant differences. Cohen's $d$ was used to determine the effect size of the means. An effect size $<0.2$ reflects a negligible difference, $\geq 0.2$ and $<0.5$ reflects a small difference, $\geq 0.5$ and $<0.8$ reflects a moderate difference, and $\geq 0.8$ suggests large difference. The relation between skeletal age and the upper and lower limbs explosive strength was verified by Pearson's correlation. A coefficient $r<0.1$ reflects trivial correlation; $0.1-0.3$ small; $0.3-0.5$ moderate; $0.5-0.7$ strong; 0.7 - 0.9 very strong; 0.9 - 0.99 almost perfect; and 1.0 perfect. In order to identify relationship of skeletal age (predictor variable) on dependent variables, upper and lower limb explosive strength, we used simple linear regression with skeletal age isolated and multiple regression adjusted by body mass and stature. Considering anthropometric variables in the model, the FIV index was verified to diagnose the multicollinearity between the predictive variables (FIV <10). For each sex, two regression analyzes per dependent variable were performed. A post hoc statistical power analysis for differences in explosive strength among the maturation levels was conducted to determine achieved power, based on the investigated sample size, an alpha of 0.05 , and the achieved effect size. Regarding boys, for a univariate ANOVA analysis, achieved power for the main effect of group was $99 \%$ and $81 \%$ for upper limbs and lower limbs, respectively. Regarding girls, achieved power for the main effect of group was $100 \%$ and $84 \%$ for upper limbs and lower limbs, respectively. Data analysis was performed using Statistical Package for Social Sciences (SPSS) version 19.0 (IBM Corp. Released 2010, IBM SPSS Statistics for Windows (New York - USA) and the significance level set was $\mathrm{p}<0.05$. 


\section{RESULTS}

Table 1 reports comparison of physical and motor characteristics according to sex, as well as boys and girls distribution according to maturational stages. It is possible to identify that girls presented highest values for skeletal age compared to the boys $\left(\mathrm{F}_{(1.237)}=13.74\right.$; partial $\left.\eta^{2}=0.055\right)$, thus a higher prevalence of girls at accelerated maturational status was observed in relation to the boys focused at normal and late stages. Concomitantly, higher values were found for girls height when compared to boys, even with similar chronological ages $\left(F_{(1.237)}=4.74\right.$; partial $\left.\eta^{2}=0.020\right)$.

Table 1. Characteristics of the sample according to sex.

\begin{tabular}{|c|c|c|c|c|}
\hline \multirow[b]{2}{*}{ Variables } & Boys $(n=101)$ & Girls $(n=138)$ & \multirow[b]{2}{*}{ p } & \multirow[b]{2}{*}{ ES } \\
\hline & $\begin{array}{c}\text { Mean / } \\
\text { Standard Deviation }\end{array}$ & $\begin{array}{c}\text { Mean / } \\
\text { Standard Deviation }\end{array}$ & & \\
\hline Chronological age (years) & $11.92 \pm 1.29$ & $12.10 \pm 1.53$ & 0.33 & 0.12 \\
\hline Skeletal age (years) & $11.41 \pm 1.95$ & $12.56 \pm 2.62$ & $<0.001^{*}$ & 0.50 \\
\hline Body mass $(\mathrm{kg})$ & $42.21 \pm 13.48$ & $45.21 \pm 12.02$ & 0.071 & 0.23 \\
\hline Height (m) & $1.48 \pm 0.01$ & $1.51 \pm 0.10$ & $0.030^{*}$ & 0.42 \\
\hline Body mass index (kg/m2) & $18.85 \pm 4.21$ & $19.45 \pm 3.72$ & 0.227 & 0.15 \\
\hline ULS (m) & $2.06 \pm 0.80$ & $2.04 \pm 0.75$ & 0.907 & 0.02 \\
\hline LLS (cm) & $27.09 \pm 9.00$ & $25.38 \pm 6.56$ & 0.092 & 0.21 \\
\hline Maturational Stage & $\mathrm{N}(\%)$ & $\mathrm{N}(\%)$ & & \\
\hline Delayed & $41(40.6)$ & $24(17.4)$ & & \\
\hline Normal & $51(50.5)$ & $60(43.5)$ & & \\
\hline Accelerated & $09(8.9)$ & $54(39.1)$ & & \\
\hline
\end{tabular}

ULS= upper limbs explosive strength; LLS= lower limbs explosive strength; ES= effect size; *statistical difference $p<0.05$

Figure 1 reports comparison between upper and lower limbs explosive strength of boys and girls according to their maturational stage. Differences in upper limbs explosive strength performance among boys maturational stages were observed $\left(\mathrm{F}_{(2.98)}=10.8 ; \mathrm{p}<0.001 ;\right.$ partial $\left.\eta^{2}=0.181\right)$ and girls $\left(F_{(2.135)}=26.6 ; p=<0.001 ;\right.$ partial $\left.\eta^{2}=0.283\right)$, as well as boys lower limbs explosive performance force $\left(\mathrm{F}_{(2.98)}=10.8 ; \mathrm{p}=0.007\right.$; partial $\left.\eta^{2}=0.095\right)$ and girls $\left(F_{(2.135)}=5.5 ; p=0.005\right.$; partial $\left.\eta^{2}=0.075\right)$. Post hoc analysis showed delayed maturational development boys had the worst performance for medicine ball throwing test compared to normal group ( $\mathrm{p}=0.001 ; d=0.94)$ and accelerated ones ( $\mathrm{p}=0.001 ; d=0.96)$, similar to results obtained for vertical jump test, delayed versus normal group $(\mathrm{p}=0.42 ; d=0.54)$ and delayed versus accelerated $(\mathrm{p}=0.24 ; d=1.1)$. For girls, explosive strength performance was lower for delayed maturational stage group when compared to normal $(\mathrm{p}=0.001 ; d=0.97)$ and accelerated stage $(\mathrm{p}<0.01 ; d=2.01)$. Delayed maturational stage girls had worse lower limbs explosive strength performance when compared to accelerated ( $\mathrm{p}=0.007 ; d=0.75$ ).

Table 2 shows correlation between skeletal age and upper and lower limbs explosive strength of boys and girls. It was observed a positive sig- 
nificant relation between skeletal age and upper and lower limbs explosive strength in both genders, which was observed moderate correlation coefficients for LLS in boys and girls, while strong correlation coefficients were found for ULS.
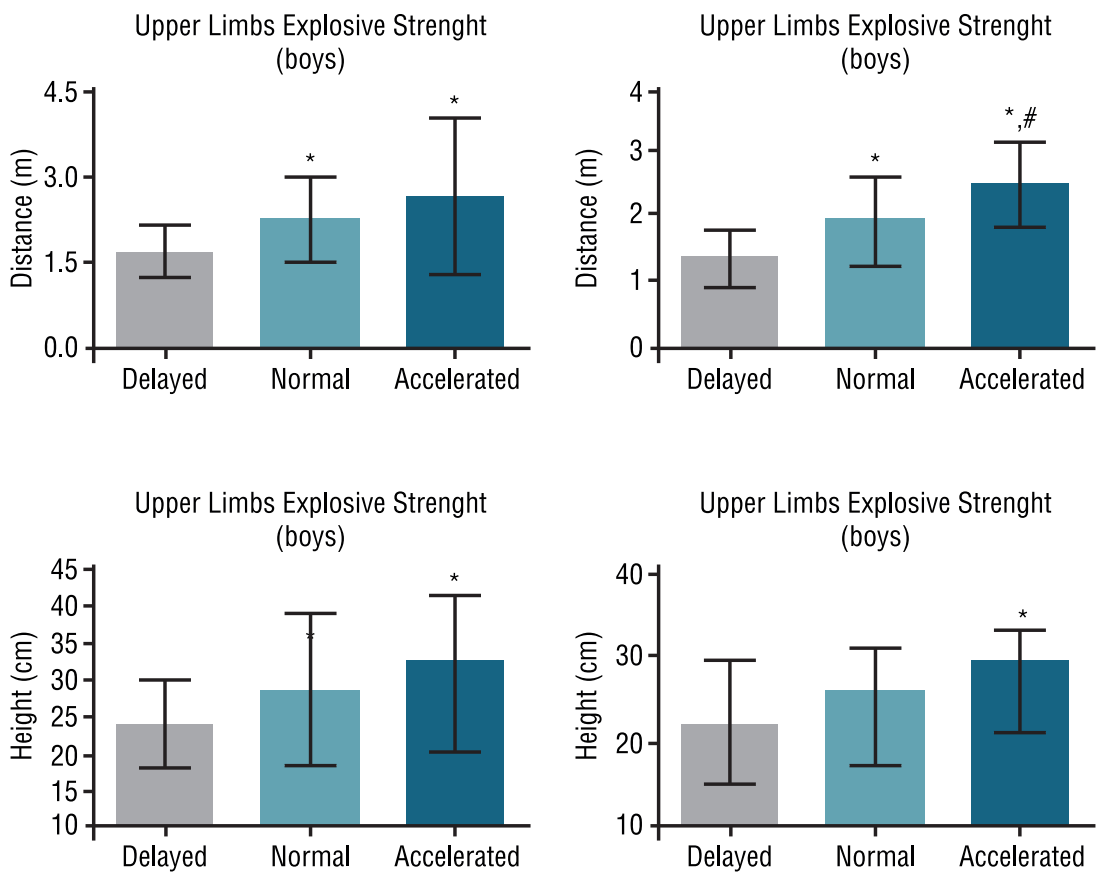

Figure 1. Comparison of explosive strength of upper and lower limbs according to the biological development of boys and girls

ULS = upper limbs explosive strength; LLS= lower limbs explosive strength; * = statistical difference vs delayed $(p<0.05) ; \#=$ statistical difference vs normal $(p<0.05)$.

Table 2. Correlation of skeletal age with the explosive strength of upper and lower limbs according to sex.

\begin{tabular}{lll}
\hline Variables & Boys & Girls \\
\hline & \multicolumn{2}{c}{ Skeletal Age } \\
\hline ULS $(\mathrm{m})$ & $0.600^{*}$ & $0.672^{*}$ \\
LLS $(\mathrm{cm})$ & $0.438^{*}$ & $0.401^{*}$ \\
\hline
\end{tabular}

ULS= upper limbs explosive strength; LLS= lower limbs explosive strength; * statistical difference $\mathrm{p}<0.001$.

Table 3 reports a regression model with upper and lower limbs explosive strength variables considering skeletal age as an independent variable. Isolated, skeletal age shared respectively $36 \%$ and $45.2 \%$ of variance of upper limbs explosive strength performance for boys and girls; skeletal age shows lower regression coefficient for upper limbs explosive strength performance in both, boys (19.2\%) and girls (16.1\%). A variance of $41.4 \%$ and $49.4 \%$ was observed to performance boys and girls lower limb explosive strength, respectively, after anthropometric variables model adjustment, body mass, height and skeletal age (model 2). Whereas, lower limbs explosive strength there was a lower correlation coefficient, totaling $28.1 \%$ for boys and $21.9 \%$ for girls. 
Table 3. Linear regression model for the variables explosive strength of upper and lower limbs by the variable independent skeletal age of boys and girls.

\begin{tabular}{|c|c|c|c|c|c|}
\hline \multirow{3}{*}{ Dependent Variables } & \multicolumn{5}{|c|}{ Model 1} \\
\hline & \multicolumn{5}{|c|}{ Boys (Skeletal Age) } \\
\hline & $\mathrm{R}^{2}$ & B unstandardized & Standard error & IC95\% & $p$ \\
\hline ULS (m) & 0.360 & 0.243 & 0.033 & $0.178-0.308$ & $<0.001$ \\
\hline \multirow[t]{2}{*}{$\operatorname{LLS}(\mathrm{cm})$} & 0.192 & 2.025 & 0.417 & $0.157-0.229$ & $<0.001$ \\
\hline & \multicolumn{5}{|c|}{ Girls (Skeletal Age) } \\
\hline ULS (m) & 0.452 & 0.193 & 0.018 & $1.197-2.853$ & $<0.001$ \\
\hline \multirow[t]{2}{*}{ LLS (cm) } & 0.161 & 1.003 & 0.197 & $0.614-1.392$ & $<0.001$ \\
\hline & \multicolumn{5}{|c|}{ Model 2} \\
\hline \multirow[t]{2}{*}{ Dependent Variables } & \multicolumn{5}{|c|}{ Boys (Skeletal Age + Anthropometric variables) } \\
\hline & $\mathrm{R}^{2}$ & B unstandardized & Standard error & IC95\% & $p$ \\
\hline ULS (m) & 0.414 & 0.133 & 0.058 & $0.018-0.247$ & 0.023 \\
\hline \multirow[t]{2}{*}{ LLS (cm) } & 0.281 & 2.813 & 0.727 & $1.370-4.257$ & $<0.001$ \\
\hline & \multicolumn{5}{|c|}{ Girls (Skeletal Age + Anthropometric variables) } \\
\hline ULS (m) & 0.494 & 0.139 & 0.035 & $0.069-0.208$ & $<0.001$ \\
\hline LLS (cm) & 0.219 & 0.963 & 0.381 & $0.210-1.716$ & 0.013 \\
\hline
\end{tabular}

ULS= upper limbs explosive strength; LLS= lower limbs explosive strength; IC95\%= confidence interval $95 \%$ model $1=$ skeletal age; model $2=$ adjusted by anthropometric variables (body mass and height).

\section{DISCUSSION}

This study verified the effect of young athletes maturational stages on upper and lower limb explosive strength performance. Despite the same chronological age group, our data show a strong effect of accelerated maturation on upper limb explosive force performance for both sexes, compared to delayed maturational stage subjects. Regarding to lower limbs explosive strength strong and moderate effect of accelerated maturation was observed for boys and girls, respectively, when compared to delayed maturational stages. After regression analysis, our findings demonstrated that biological maturation, estimated by skeletal age, alone, shared $36 \%$ and $45.2 \%$ of variance of upper limbs explosive strength performance for boys and girls, respectively. Besides, it was also observed that skeletal age alone showed only $19.2 \%$ and $16.1 \%$ of variance in lower limb explosive strength performance for boys and girls, respectively.

Previous studies have reported similar data indicating a linear increase in explosive strength for young people with accelerated $>$ normal> delayed maturational stage $e^{5,7}$. During adolescence, physical performance is correlated with biological development ${ }^{1,6,10,11}$. In this way, our findings predict that during biological development, there is an increase in upper and lower limbs explosive strength. In fact, some mechanisms can be attributed to explain the obtained values for young people explosive strength during biological development. They include the largest responses of anabolic hormones, such as testosterone ${ }^{20}$ and structural changes in muscle architecture, resulting significant changes in type I to type II fibers proportion ${ }^{21,22}$, observed in younger age. Volver et al. ${ }^{23}$, further complement 
that the anabolic androgenic actions in the pubertal period stimulate the development of type II muscular fibers, responsible for explosive force generation. However, because of their invasive nature, metabolic responses in children and adolescents according to maturational development are limited. However, based on the aforementioned studies, it is possible to hypothesize that lower hormonal circulation and amounts of type fibers II, may explain, in part, the differences in explosive strength performance among maturational ${ }^{24}$.

Body changes in height and body mass inherent to maturational process $^{5,10}$ have been proposed by some authors to explain differences in performance and muscle strength according to anthropometric variables $^{6,11}$. However, after body mass and height inclusion to the model, a small correlation coefficient increase was evidenced, demonstrating that skeletal age is able to explain the greater variance in upper and lower limbs explosive strength, with lower variance shared for vertical jump. Previous studies of our group ${ }^{10,25}$ showed similar relation between lower limbs explosive strength and biological development has presented lower coefficients when compared to upper limbs explosive strength. Till et al. ${ }^{5}$ did not verify interaction effect for maturational group $\mathrm{x}$ time effect for vertical jump when they compared annually young rugby players performance in respective categories (under 13, under 14 and under 15) according to maturational stage. Probably, this lower relation of skeletal age with vertical jump performance is attributed to a greater neuromuscular factors contribution attributed commonly to tendon rigidity ${ }^{26}$. On the other hand, It was observed a low significant positive relation for this specific volleyball actions, with a strong and moderate effect reported for boys and girls univariate analysis respectively. Therefore, maturational influence on lower limb explosive force performance is not yet clear in literature, suggesting future investigations in order to elucidate possible mechanisms that explain lower limbs explosive strength differences in this population, mainly due to the importance of this component in sports. . .

Ability to play the highest power of lower and upper limbs is identified as critical to success in volleyball game and is often requested for athletes specific game actions like spike, block, serve and set ${ }^{26,27}$. Among the discriminating functions of volleyball, block and spike in attack and counterattack phase are predictors that distinguish sets victory and defeat ${ }^{28}$. Additionally, it is possible to suggest that the upper and lower limb explosive strength performance plays an important role in this discriminant volleyball functions efficiency ${ }^{26,29}$ it is likely that young athletes with better performance for these attributes may have advantages in sports selection process due to the importance of maturational development for this athletic component. Corroborating this idea, Torres-Unda et al. ${ }^{2}$, demonstrated that selected basketball athletes have greater maturational development than the non-selected. However, it should be pointed out that this selection criterion, using only athlete's physical and motor attributes, could induce a potential long-term planning mistake ${ }^{1}$. Recently, longitudinal design 
studies have shown that athletes at delayed development demonstrated higher increment for upper and lower limb power test performance compared to normal and accelerated development ${ }^{5,30}$. These data suggest that a potential development window may exist for subjects with delayed maturation, contradicting current criteria for young athletes selection programs. Therefore, the importance of monitoring biological development during young athletes' selection process is emphasized in order to avoid exclusion of a potential athlete in a near future, who can match or overcome their peers with accelerated development.

In conjunction with previous results our findings confirm the importance of evaluating maturational development for coaches and sports professionals during young athletes selection and sports orientation process considering that explosive strength performance is different according to the biological development. Therefore, sports professionals have a simple greater practical applicability tool based on anthropometric measurements as an alternative to estimate the biological development according to gold standard method of $\mathrm{x}$-ray of the wrist, and consequently improving choices during the young athletes training process. It is advisable to expect for better results from delayed young athletes during maturational process until they reach more advanced maturity levels in order to avoid an early exclusion of a potential athlete. In spite of study relevant information, some limitations must be pointed out, as transversal design, what became impossible to clarify a relation of cause and effect between maturation and athletes motor development. Besides that, our findings should be analyzed with caution, considering the use of indirect methods for explosive force evaluation, however, it is important to note that methods used for this study are widely used in literature and also have a high reliability degree.

\section{CONCLUSION}

It is evidenced that biological development, estimated by skeletal age, presents a significant positive relation to explosive upper and lower limbs explosive performance, although a smaller relation to lower limbs explosive strength was found. In this sense, our findings reinforce necessity to evaluate maturation during young athlete's selection processes, combined to other aspects, such as chronological age, in order to reduce potential choice misunderstandings, especially in those sports that require further upper limb potency development. It is also worth noting that this is a starting study, which proposes to longitudinally evaluate this sample in order to know if our model will be confirmed.

\section{REFERENCES}

1. Malina RM, Rogol AD, Cumming SP, Coelho E Silva MJ, Figueiredo AJ. Biological maturation of youth athletes: assessment and implications. Br J Sports Med 2015;49(13):852-9.

2. Torres-Unda J, Zarrazquin I, Gil J, Ruiz F, Irazusta A, Kortajarena M, et al. Anthropometric, physiological and maturational characteristics in selected elite 
and non-elite male adolescent basketball players. J Sports Sci 2013;31(2):196-203.

3. Sheppard JM, Gabbett T, Taylor KL, Dorman J, Lebedew AJ, Borgeaud R. Development of a repeated-effort test for elite men's volleyball. Int J Sports Physiol Perform 2007;2(3):292-304.

4. Pereira A, Costa AM, Santos P, Figueiredo T, João PV. Training strategy of explosive strength in young female volleyball players. Medicina 2015;51(2):126-31.

5. Till K, Cobley S, O' Hara J, Cooke C, Chapman C. Considering maturation status and relative age in the longitudinal evaluation of junior rugby league players. Scand J Med Sci Sports 2014;24(3):569-76.

6. Beunen G, Ostyn M, Simons J, Renson R, Van Gerven D. Chronological and biological age as related to physical fitness in boys 12 to 19 years. Ann Hum Biol. 1981;8(4):321-31.

7. Lefevre J, Beunen G, Steens G, Claessens A, Renson R. Motor performance during adolescence and age thirty as related to age at peak height velocity. Ann Hum Biol 1990;17(5):423-35.

8. Malina RM, Meleski BW, Shoup RF. Anthropometric, body composition, and maturity characteristics of selected school-age athletes. Pediatr Clin North Am 1982;29(6):1305-23.

9. Malina R, Bouchard C, Bar-Or O. Growth, maturation, and physical activity. Champaign: Human Kinetics; 2004.

10. Cabral S de AT, Cabral BG de AT, Pinto VCM, Andrade RD de, Borges MV de O, Dantas PMS. Relação da idade óssea com antropometria e aptidão física em jovens praticantes de voleibol. Rev Bras Cienc Esporte 2016;38(1):69-75.

11. Katzmarzyk PT, Malina RM, Beunen GP. The contribution of biological maturation to the strength and motor fitness of children. Ann Hum Biol 1997;24(6):493-505.

12. Lloyd RS, Oliver JL, Faigenbaum AD, Myer GD, De Ste Croix MBA. Chronological age vs. biological maturation: implications for exercise programming in youth. J Strength Cond Res 2014;28(5):1454-64.

13. Cabral BG de AT, Cabral S de AT, Vital R, Lima KC de, Alcantara T, Reis VM, et al. Equação preditora de idade óssea na iniciação esportiva através de variáveis antropométricas. Rev Bras Med Esporte 2013;19(2):99-103.

14. Perini T, Oliveira G, Ornellas J, Oliveira F. Cálculo do erro técnico de medição em antropometria. Rev Bras Med Esporte 2005;11(1):81-5.

15. Marfell-Jones M, Stewart A, Ridder J de. International standards for anthropometric assessment. International Society for the Advancement of Kinanthropometry; 2012;

16. Gaya A, Silva G. Projeto Esporte Brasil PROESP-Bateria de Medidas e Testes Somatomotores do Proesp. Porto Alegre- RS. 2009; Avaiable from: <https://www. ufrgs.br/proesp/como-aplicar-o-proesp.php> [2016 ago 20].

17. Tillaar van den R, Marques MC. Reliability of seated and standing throwing velocity using differently weighted medicine balls. J Strength Cond Res 2013;27(5):1234-8.

18. Komi P V. Força e potência no esporte. Artmed Editora; 2008.

19. Markovic G, Dizdar D, Jukic I, Cardinale M. Reliability and factorial validity of squat and countermovement jump tests. J Strength Cond Res 2004;18(3):551-5.

20. Baldari C, Di Luigi L, Emerenziani GP, Gallotta MC, Sgrò P, Guidetti L. Is explosive performance influenced by androgen concentrations in young male soccer players? Br J Sports Med 2009;43(3):191-4.

21. Lexell J, Sjöström M, Nordlund AS, Taylor CC. Growth and development of human muscle: a quantitative morphological study of whole vastus lateralis from childhood to adult age. Muscle Nerve 1992;15(3):404-9.

22. Oertel G. Morphometric analysis of normal skeletal muscles in infancy, childhood and adolescence. An autopsy study. J Neurol Sci 1988;88(1-3):303-13.

23. Volver A, Viru A, Viru M. Sexual maturation effect on physical fitness in girls: a longitudinal study. Biol Sport 2010;27(1):11-5. 
24. Ratel S, Duché $\mathrm{P}$, Williams CA. Muscle fatigue during high-intensity exercise in children. Sport Med 2006;36(12):1031-65.

25. Cabral BG, Cabral SA, Medeiros RM, Alcatara T, Dantas PMS. Relação da maturação com a antropometria e aptidão física na iniciação desportiva. Motrici 2013;9(4):12-21.

26. Ziv G, Lidor R. Vertical jump in female and male volleyball players: A review of observational and experimental studies. Scand J Med Sci Sport 2010;20(4):556-67.

27. Sheppard JM, Cronin JB, Gabbett TJ, McGuigan MR, Etxebarria N, Newton RU. Relative importance of strength, power, and anthropometric measures to jump performance of elite volleyball players. J Strength Cond Res 2008;22(3):758-65.

28. Marelic N, Resetar T, Jankovic V. Discriminant analysis of the sets won and the sets lost by one team in A1 Italian volleyball league - a case study. Kinesiology 2004;36(1):75-82.

29. Forthomme B, Croisier J-L, Ciccarone G, Crielaard J-M, Cloes M. Factors correlated with volleyball spike velocity. Am J Sports Med 2005;33(10):1513-9.

30. Pinto Júnior JAD, Sousa MSC, Gaya ACA, Alves JVMH, Nascimento JA. Idade óssea, cronológica e desempenho físico de jovens atletas. Rev Bras Cienc Mov 2014;22(1):37-44.

\section{CORRESPONDING AUTHOR}

Petrus Gantois

Rua das Amapolas, 59078-150,

Capim Macio-RN, Brasil

E-mail:pgm.gantois@gmail.com 